\title{
Effect of microstructure on corrosion behavior of dual-phase steels
}

\author{
E. Salamci ${ }^{1 *}$, S. Candan ${ }^{2}$, F. Kabakci ${ }^{3}$ \\ ${ }^{1}$ Department of Mechanical Engineering, Gazi University, 06570 Ankara, Turkey \\ ${ }^{2}$ Department of Mechanical and Manufacturing Engineering, Bilecik University, Bilecik, Turkey \\ ${ }^{3}$ Alapli Vocational High School, Bulent Ecevit University, Zonguldak, Turkey
}

Received 16 December 2015, received in revised form 7 April 2016, accepted 15 April 2016

\begin{abstract}
Dual phase (DP) steels with different volume fractions of martensite and epitaxial ferrite were produced in different intercritical annealing temperatures and cooling rates. Corrosion behaviors of four different DP steels were investigated in $3.5 \% \mathrm{NaCl}$ solution by using potentiodynamic polarization and immersion tests. The results showed that both amounts of martensite and epitaxial ferrite have an influence on the corrosion behavior of DP steels. It was observed that corrosion resistance increased considerably with the presence of epitaxial ferrite as compared to dual phase steel containing non-epitaxial ferrite. On the other hand, the corrosion resistance of DP steels decreased with an increase in the martensite volume fraction $(\mathrm{MVF})$.
\end{abstract}

K e y w or d s: dual-phase steel, epitaxial ferrite, martensite, corrosion

\section{Introduction}

Low carbon Dual Phase (DP) steels developed in the 1970s have aroused considerable attention in the last three decades. Compared to the High Strength Low Alloy (HSLA) steels, they display improved strength, ductility and formability characteristics [1-7]. These properties make them attractive for weight-saving applications in automotive industry. By using dual phase steel sheets, vehicle weight can be reduced, and significant savings in fuel consumption can be obtained. One another application area might be the construction sector where reinforcing steels in concrete would be desirable to have both superior mechanical properties and corrosion resistance.

DP steel is delineated by the composite microstructure comprising $20-25 \%$ hard martensite particles in a soft ferritic matrix. They are mainly produced by heating the low carbon steel between $A_{\mathrm{C} 1}$ and $A_{\mathrm{C} 3}$ temperatures in the austenite plus ferrite phase field followed by rapid cooling in order to transform the austenite to martensite. The strength of DP steels increases with increasing the volume fraction of martensite phase $[8,9]$.

It is possible to control the range of transforma- tion products which can be formed from the austenite subsequent intercritical annealing by varying intercritical annealing temperature and cooling rate. The austenite entirely transforms to martensite resulting in the duplex structure of ferrite and martensite at the higher cooling rates. During the slow cooling rates, the austenite firstly transforms to new ferrite which grows epitaxially on the retained or intercritical ferrite without a nucleation step. Then, depending on the alloy content and cooling rate, the remaining austenite transforms to martensite, bainite, and/or pearlite with continued cooling [10]. Transformed ferrite from the austenite during the slow cooling is also called epitaxial ferrite. It has been shown that there is no structural interface between the two types of ferrite, and the epitaxial ferrite differs from the retained ferrite in terms of composition [11, 12]. Previous investigations have shown that ductility of dual phase steels increases with a small decrease in the strength, as the epitaxial ferrite content increases [13-15].

Ferritic-martensitic steels which possess excellent mechanical properties can respond to higher corrosion resistance requirements which cannot be obtained in ferritic-pearlitic steels [16]. In addition to their incomparable combination of mechanical properties, the cor-

*Corresponding author: tel.: +90 312 5823452; fax: +90 312 2319810; e-mail address: esalamci@gazi.edu.tr 
Table 1. Chemical composition of the steel (wt.\%)

\begin{tabular}{ccccccccc}
\hline $\mathrm{C}$ & $\mathrm{Mn}$ & $\mathrm{P}$ & $\mathrm{S}$ & $\mathrm{Si}$ & $\mathrm{Cu}$ & $\mathrm{Cr}$ & $\mathrm{Ni}$ \\
\hline 0.09 & 1.65 & 0.015 & 0.013 & 0.55 & 0.02 & 0.07 & 0.69 \\
\hline
\end{tabular}

rosion resistance of DP steels is critically important for structural and constructional purposes. It is inevitable that the reinforcing steels in concrete suffer from corrosion over time. For this reason, the investigation of the steels with higher corrosion resistance has been attracting the attention of researchers. Although extensive researches concerning microstructure and mechanical properties exist in the literature, the investigations on corrosion behavior of DP steels are quite a few. Trejo et al. [17] have studied corrosion susceptibility of a DP steel in concrete and observed that the DP steel bar has better atmospheric corrosion resistance than a standard billet bar consisting of ferrite and pearlite phases. Zhang et al. [18] also observed better corrosion resistance in the DP weathering steel. Sarkar et al. [19] have investigated electrochemical corrosion behavior of micro-alloyed DP steel in $3.5 \% \mathrm{NaCl}$ solution and determined that an increase in martensite content and refinement of martensite morphology decreases corrosion resistance. Osorio et al. [20] have also studied electrochemical corrosion behavior of low carbon steel in three different heat treated and as-received conditions by carrying out electrochemical impedance spectroscopy (EIS) and polarization test. They found that normalized and annealed steels have the highest and lowest corrosion resistances respectively and the DP steel has slightly smaller corrosion resistance than annealed and as-received steels. Bhagavathi et al. [21] have recently reported that DP steels are more resistant to corrosion than the ferrite-pearlite steel.

The main purpose of this study is to explore the effect of the epitaxial ferrite on the corrosion behavior of DP steel which has not been thoroughly assessed in the literature yet. In this work, corrosion behaviors of DP steel microstructures which are produced at two different intercritical annealing temperatures followed by rapid and slow cooling rates are investigated.

\section{Experimental procedure}

The chemical composition of the steel used in the experiments is given in Table 1. The material was produced in an induction furnace and poured into silica sand mold as a block of $26 \times 300 \times 300 \mathrm{~mm}^{3}$ in size. The block was then cut into smaller pieces of $26 \times 26 \times 300 \mathrm{~mm}^{3}$. These pieces were hot rolled in which the thickness of each was reduced to $4 \mathrm{~mm}$.

The critical annealing temperatures, $A_{\mathrm{C} 1}$ and $A_{\mathrm{C} 3}$, were identified as 711 and $862^{\circ} \mathrm{C}$ by using Andrew's empirical formulas [22]. The samples of
$10 \times 10 \mathrm{~mm}^{2}$ size were heat treated. Each specimen, namely WQ715, FC725, WQ725, and FC752, was coded according to the applied heat treatment procedures. The left-hand letters represent the cooling media, and the right-hand numbers represent the intercritical annealing temperatures.

The heat treated samples were ground, polished and etched in $2 \%$ nital solution of $2 \%$ nitric acid in $98 \%$ ethanol for microstructural characterization by using a light microscope. After etching with $2 \%$ nital, the samples were further etched in a solution of $10 \%$ sodium metabisulfite in $90 \%$ pure water in order to reveal the martensite structure. The boiling alkaline chromate etching method developed by Lawson et al. was used to differentiate the epitaxial ferrite from the retained ferrite [23]. This method is a two-step procedure consisting of a first etch in a solution of $4 \%$ picral for 40-60 s, followed by a second etch in a boiling alkaline chromate solution for 4-10 min. The volume fraction of martensite and epitaxial ferrite were determined by using a point counting on etched metallographic sections. Almost 1000 points were counted by using Swift mark point counter.

The immersion tests were carried out by suspending the square shaped samples $\left(10 \times 10 \mathrm{~mm}^{2}\right.$ and $1.5 \mathrm{~mm}$ thick) in a still solution of $3.5 \mathrm{wt} . \% \mathrm{NaCl}$ in deionized water exposed to atmospheric air. The results of the corrosion tests were evaluated by mass loss measurements, performed following the ASTM G31 recommended practice. The surfaces of the specimens were abraded on 1200 mesh emery paper, polished with $1 \mu \mathrm{m}$ diamond paste, washed and ultrasonically rinsed in distilled water prior to the immersion tests. Exposure time for the tests was 1, 3, 7, 14, and 28 days. The surfaces of the specimens were gently brushed before ultrasonically cleaning in distilled water at the end of each exposure time. After cleaning, they were dried and weighed. Mass loss of the samples was then normalized in the unit of $\mathrm{mg} \mathrm{cm}^{-2}$, by considering the total surface area of the samples. For the potentiodynamic polarization measurements, machined samples of $15 \mathrm{~mm}$ in length and $10 \mathrm{~mm}$ in diameter were connected to the copper wire and embedded in an epoxy resin holder. The potentiodynamic curves were performed by means of a Gamry model PC4/300 mA potentiostat/galvanostat controlled by a computer with DC105 corrosion analysis software. The specimens were prepared in the same way as that for the mass loss evaluation. Embedded specimens in epoxy resin were utilized as working electrodes. A carbon $\operatorname{rod}(6 \mathrm{~mm}$ in diameter) and a saturated calomel electrode (SCE) were used as a counter electrode and 

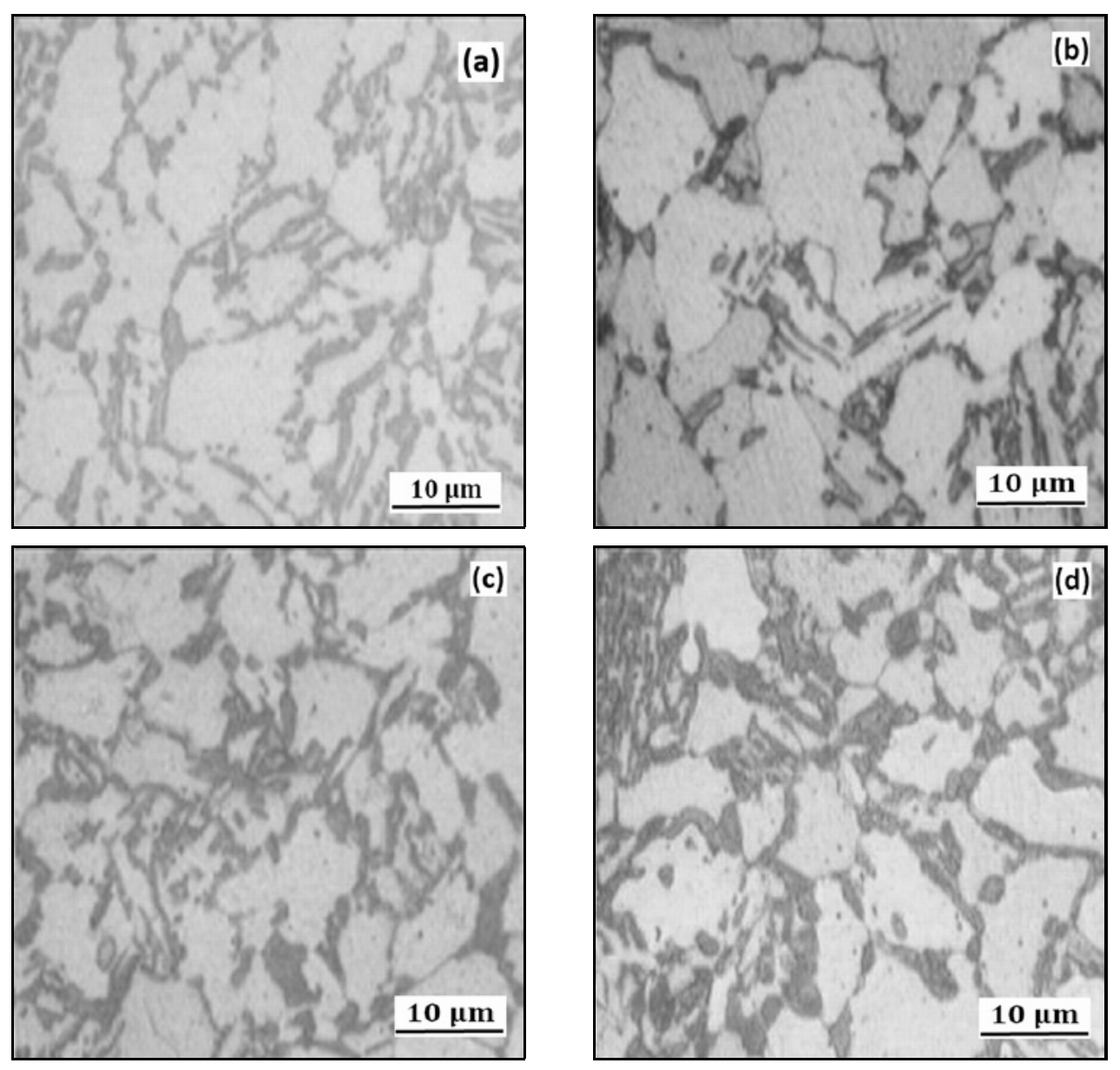

Fig. 1. Optical micrographs of (a) WQ715, (b) FC725, (c) WQ725, (d) FC752 DP steel samples (etched in nital $2 \%$ ).

a reference electrode, respectively. Experiments were performed at room temperature in a glass cell containing $3.5 \% \mathrm{NaCl}$ solution, $p H \cong 7$. For electrochemical measurements, the specimen was immersed in the solution for $60 \mathrm{~min}$. prior to polarization, by which the time for a stable potential (open circuit potential "OCP") was monitored. With reference to saturated calomel electrode (SCE), potentiodynamic polarization curves were generated by sweeping the potential from cathodic to the anodic direction at a scan rate of $1 \mathrm{mV} \mathrm{s}^{-1}$, starting from $\sim 0.40$ up to $0.80 \mathrm{~V}$. Each data point for both immersion and potentiodynamic polarization tests represents at least average of three different measurements. Corrosion potentials $\left(E_{\text {corr }}\right)$ and the corrosion current densities $\left(I_{\text {corr }}\right)$ were calculated by using instantaneous Tafel-type fit GamryDC105 Corrosion analysis software.

\section{Results and discussion}

\subsection{Micro structure}

Austenite at intercritical annealing temperatures transforms to martensite and epitaxial ferrite de- pending on cooling rate. Optical micrographs of the WQ715, FC725, WQ725, and FC752 etched with nital $2 \%$ are displayed in Figs. 1a-d, respectively. In these micrographs, martensite appears as dark color in a light ferrite matrix. It can be seen that martensite particles distribute along the ferrite grain boundaries. In the specimens WQ715 and WQ725, most of the austenite transformed to martensite by rapid quenching from 715 and $725^{\circ} \mathrm{C}$. Martensite was replaced by epitaxial ferrite with the decreasing cooling rates. Slower cooling from 725 and $752^{\circ} \mathrm{C}$ resulted in the formation of epitaxial ferrite in addition to martensite. Retained and epitaxial ferrites were distinguished by using Lawson etchant. Figures 2a,b show the micrographs of the FC725 and FC752 etched with $4 \%$ picral + hot alkaline chromate revealing martensite as black, epitaxial ferrite white and retain ferrite gray. It can be seen from Figs. 2a,b that martensite is surrounded by a ring of epitaxial ferrite.

In the present study, the critical cooling rate for martensite formation is quite low when compared to previous studies [23-27]. Figures 1b,d show that a significant amount of austenite transformed to martensite even at the lower cooling rates (furnace cooling). The reason for this may be due to high $\mathrm{Mn}$ and $\mathrm{Ni}$ 
Table 2. Applied heat treatment procedure and quantitative metallographic data for DP steel samples

\begin{tabular}{ccccc}
\hline Specimen code & Intercritical annealing temperature $\left({ }^{\circ} \mathrm{C}\right)$ & Cooling media & Martensite $(\%)$ & Epitaxial ferrite $(\%)$ \\
\hline WQ715 & 715 & Water & 25 & - \\
FC725 & 725 & Furnace & 25 & 10 \\
WQ725 & 725 & Water & 35 & - \\
FC752 & 752 & Furnace & 37 & 15 \\
\hline
\end{tabular}
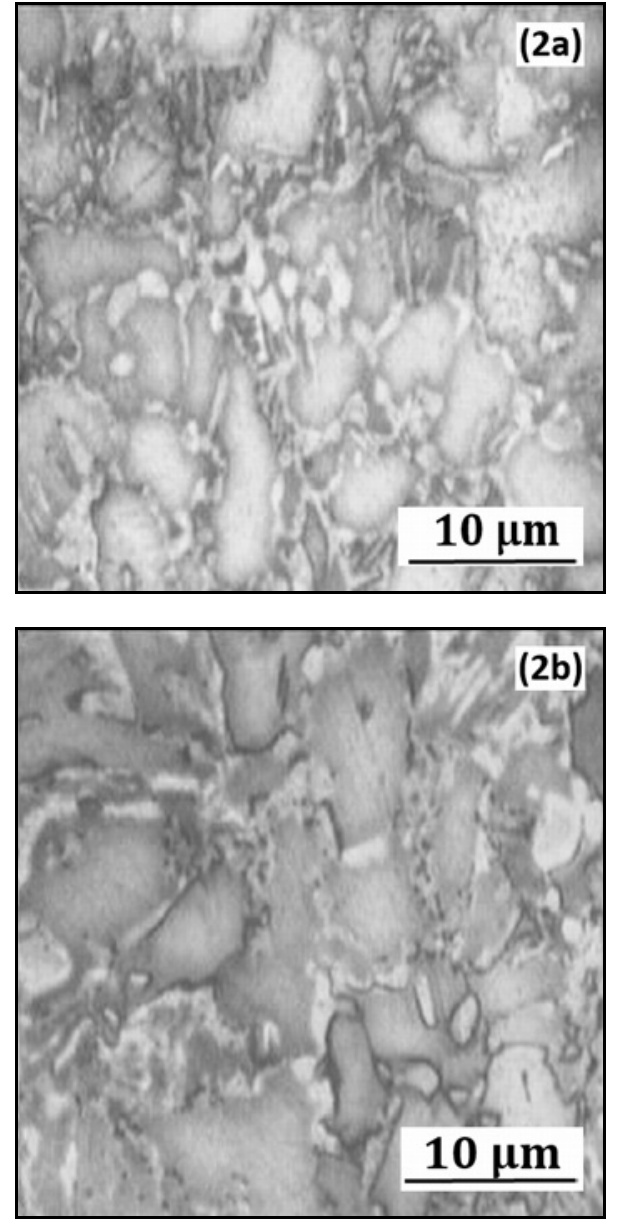

Fig. 2. Optical micrographs of (a) FC725, (b) FC752 DP steel samples (etched in $4 \%$ picral + hot chromate reagent).

contents. The concentrations of austenite stabilizing elements $(1.65 \% \mathrm{Mn}$ and $0.69 \% \mathrm{Ni})$ are higher in the steel used in the present work than those used in previous studies. It is well known that $\mathrm{Mn}$ and $\mathrm{Ni}$ alloying elements decrease the critical cooling rate and increase the hardenability of steel.

The difference in the etching response is attributed to the different content of alloying elements of the retained and the epitaxial ferrite. Korzekwa et al. [12] indicated that manganese and silicon might partition between the austenite and ferrite during intercritical annealing and thus epitaxial ferrite may inherit a higher manganese and lower silicon content when it forms from austenite cooling. These speculations were experimentally confirmed by Santofimia et al. recently [11]. They investigated the distribution of alloying elements in the present phases after intercritical annealing followed by cooling by using electron probe microanalysis in the low carbon steel. They reported that the manganese concentration is $1.6 \mathrm{wt} . \%$ in retained ferrite, $2.2 \mathrm{wt} . \%$ in epitaxial ferrite, and $2.6 \mathrm{wt} . \%$ in $\mathrm{M} / \mathrm{A}$ (martensite/austenite). The concentration profile of silicon is $0.44 \mathrm{wt} . \%$ in retained ferrite, $0.38 \mathrm{wt} . \%$ in epitaxial ferrite, $0.44 \mathrm{wt} . \%$ in retained ferrite and 0.28 wt. $\%$ in $\mathrm{M} / \mathrm{A}$. The carbon concentration is close to zero in both ferrite and $1.2 \mathrm{wt} . \%$ in $\mathrm{M} / \mathrm{A}$.

The results of the quantitative metallographic measurements are summarized in Table 2. In addition to composition, intercritical annealing temperature (ICAT) and cooling rate affect hardenability of DP steels. The martensite (austenite) volume fraction (MVF) increases with increasing the ICAT, as shown in Table 2. This can be explained by lever rule. MVF of WQ715 is found to be $25 \%$, whereas MVF of WQ725 is higher $(35 \%)$.

The cooling rate is another factor for increasing MVF at a constant ICAT. High cooling rate (water quenching) causes an increase in MVF at a constant ICAT. MVF of FC725 (slow cooling) is found to be $25 \%$, whereas MVF of WQ725 (rapid cooling) is higher $(35 \%)$ at $725^{\circ} \mathrm{C}$.

As can be seen from Table 2, the specimens FC752 and WQ725 have almost constant amount of martensite; even the specimen FC725 was produced by slow cooling. This is probably due to high hardenability of the present steel and ICAT. The specimen FC752 contains $37 \%$ and $15 \%$ MVF and epitaxial ferrite, respectively. The specimen WQ725 contains almost the same amount of martensite $(35 \%)$ and is free of epitaxial ferrite. Although both specimens have the almost constant amount of martensite, no epitaxial ferrite formation is observed in WQ725. The slow cooling rate for FC752 allows the epitaxial ferrite to grow on the existing ferrite and there is no grain boundary between the epitaxial and retained ferrite. Similarly, while WQ715 and FC725 contain the same amount of martensite (25\%), WQ715 does not contain epitaxial ferrite, FC725 contains $10 \%$ epitaxial ferrite. As shown in Table 2, the amount of epitaxial ferrite increases from $10 \%$ for FC725 to $15 \%$ for FC752. At 
Table 3. Summary of the results obtained from corrosion tests performed in $3.5 \% \mathrm{NaCl}$ solution

\begin{tabular}{|c|c|c|c|c|c|}
\hline Specimen code & $\begin{array}{l}E_{\text {corr }} \\
(\mathrm{mV})\end{array}$ & $\begin{array}{c}I_{\mathrm{corr}} \\
\left(\mu \mathrm{A} \mathrm{cm}^{-2}\right)\end{array}$ & $\begin{array}{c}\text { CR from } \\
\text { polarization test } \\
\left(\mathrm{mm} \mathrm{year}^{-1}\right)\end{array}$ & $\begin{array}{l}\text { Mass loss from } \\
\text { immersion test } \\
\text { after } 7 \text { days }(\mathrm{g})\end{array}$ & $\begin{array}{c}\text { CR from } \\
\text { immersion test } \\
\left(\mathrm{mm} \mathrm{year}^{-1}\right)\end{array}$ \\
\hline WQ715 & -73.20 & $2.11( \pm 0.2)$ & 0.050 & $1.6 \times 10^{-3}$ & 0.106 \\
\hline FC725 & -18.90 & $2.39( \pm 0.4)$ & 0.055 & $1.3 \times 10^{-3}$ & 0.086 \\
\hline WQ725 & -167.9 & $14.5( \pm 1.0)$ & 0.336 & $1.8 \times 10^{-3}$ & 0.119 \\
\hline FC752 & +37.15 & $3.11( \pm 1.4)$ & 0.072 & $1.1 \times 10^{-3}$ & 0.073 \\
\hline
\end{tabular}

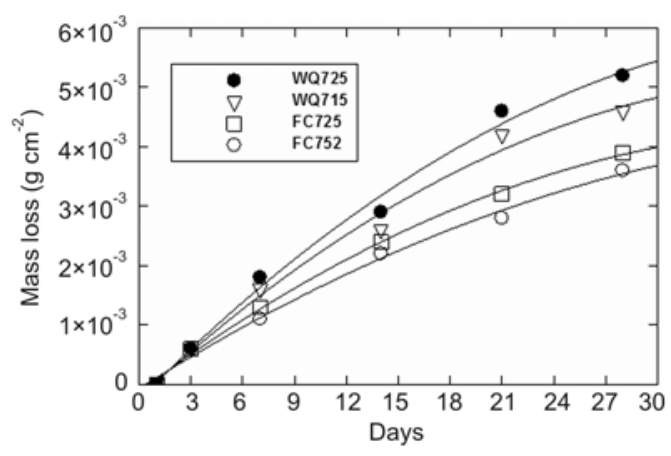

Fig. 3. Mass loss of the corroded DP steel samples from the immersion tests.

the same MVF, more epitaxial ferrite was present at higher ICAT compared to lower one. This increase in volume fraction of epitaxial ferrite is due to increase in ICAT or decrease in cooling rate. In DP heat treatment, ICAT controls the carbon concentration of austenite. Austenite (martensite) carbon content decreases with the increase of ICAT as predicted by the lever rule. The lower carbon concentration of austenite at higher ICAT results in lower hardenability. Thus more epitaxial ferrite forms instead of martensite.

\subsection{Corrosion behavior}

The mass loss of the samples increased with increasing exposure time as shown in Fig. 3. It is worth noting that mass loss of all the specimens remained almost similar for the early stages (i.e., up to 3 days) after which the mass loss was deviated as the immersion time prolonged. For example, the mass loss is approximately $30 \%$ less for FC752 in 28-days exposure time as compared to WQ725.

From immersion test results (mass loss), the corrosion rate is estimated by using the following formula [28]:

$$
\mathrm{CR}=K \frac{W}{A T D},
$$

where $\mathrm{CR}$ is the corrosion rate in $\mathrm{mm}$ year $^{-1}, K$ is a constant having value of $8.76 \times 10^{4}, W$ is a mass loss

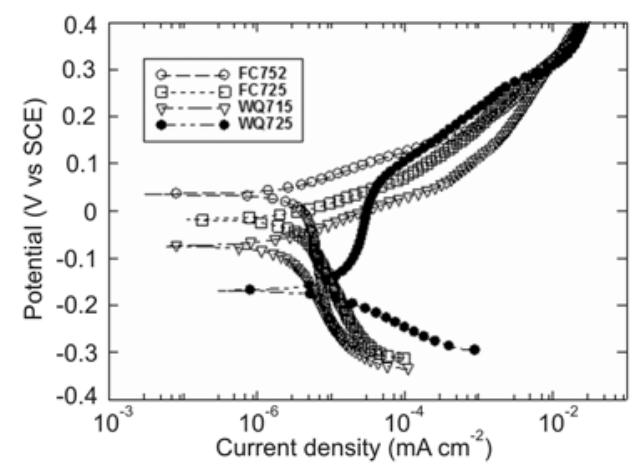

Fig. 4. Potentiodynamic polarization curves of the DP steel samples.

in $\mathrm{g}, A$ is an area of exposure $\left(1 \mathrm{~cm}^{2}\right), T$ is a time of exposure in h and $D$ is density in $\mathrm{g} \mathrm{cm}^{-3}$.

The potentiodynamic polarization behaviors of the investigated specimens in $3.5 \mathrm{wt} . \% \mathrm{NaCl}$ solution are given in Fig. 4. Corrosion potential, $E_{\text {corr }}$, and corrosion current density, $I_{\text {corr }}$ values were obtained from potentiodynamic polarization curves, and the CR (based on $I_{\text {corr }}$ ) is calculated by using the following formula [28]:

$$
\mathrm{CR}=3.27 \times 10^{-3} I_{\mathrm{corr}} \frac{\mathrm{EW}}{D},
$$

where $\mathrm{CR}$ is the corrosion rate in $\mathrm{mm}$ year ${ }^{-1}$. The equivalent weight, $\mathrm{EW}$, is approximated from the atomic weight of iron $\left(55.845 \mathrm{~g} \mathrm{~mol}^{-1}\right)$, and $D$ is the density of steel $\left(7.88 \mathrm{~g} \mathrm{~cm}^{-3}\right)$.

The calculated corrosion rates (CR) based on both the potentiodynamic polarization curves and the mass loss are summarized in Table 3 . The trend of the CR values obtained from the mass loss measurements after the immersion tests relatively agrees with the CR values obtained by the polarization method in Table 3 .

$E_{\text {corr }}$ values of WQ715, FC725, WQ725, and FC752 samples are $-73.20,-18.90,-167.9$, and $+37.15 \mathrm{mV}$, respectively (Table 3 ). It was noted that the $E_{\text {corr }}$ values of epitaxial ferrite containing samples (i.e., FC725 and FC752) had shifted to a more positive region (Fig. 4). It was also observed that the $I_{\text {corr }}$ values deviated in the range between 2.11 and $3.11 \mu \mathrm{A} \mathrm{cm}^{-2}$ for 
WQ715, FC725, and FC752 samples while $I_{\text {corr }}$ value of WQ725 was around $14.5 \mu \mathrm{A} \mathrm{cm}^{-2}$. Although more positive $E_{\text {corr }}$ and lower $I_{\text {corr }}$ values indicate that the corrosion resistance of the samples increases, the corrosion rate is directly proportional to $I_{\text {corr }}$ according to Faraday's law. In the present study, the values of $I_{\text {corr }}$ of all samples used are lower than those obtained by Sarkar et al. and Bhagavathi et al. [19, 21] indicating much better corrosion resistance. Sarkar et al. [19] reported that the $I_{\text {corr }}$ value of DP steel having $33 \%$ MVF was $32.29 \mu \mathrm{A} \mathrm{cm}^{-2}$ and it was $17.40 \mu \mathrm{A} \mathrm{cm}^{-2}$ for DP steel with $24 \% \mathrm{MVF}$ in the work of Bhagavathi et al. [21].

The corrosion of DP steels may be governed by four relative mechanisms: chemical composition, the volume fraction of martensite phase (i.e. MVF), the presence of epitaxial ferrite, and the presence of stresses.

It is known [28] that the presence of $\mathrm{Si}, \mathrm{Ni}$, and lower amount of $\mathrm{S}$ have a beneficial effect on the corrosion resistance of carbon steels. It is important to point out that the steel used in this work contained $\mathrm{Ni}$ and $\mathrm{Si}$ as well as lower $\mathrm{S}$ which may result in improved corrosion resistance of the samples.

Martensite volume fractions, MVF, of WQ715 and WQ725 samples are 25 and $35 \%$, respectively. The higher CR for WQ725 sample is attributed to MVF. Based on galvanic corrosion principles, the total surface area of the cathode (martensite) in relation to the surface area of the anode (ferrite) governs the galvanic corrosion. Therefore, any relative change in the amount of the microstructural constituents would lead to alteration in the ratio of anode to cathode areas. In literature $[17,19,20]$, the corrosion rate of DP steels increased with increasing MVF which was reported to be due to the adverse area ratio of martensite phase to ferrite phase in accordance with the present work.

However, the MVF of FC752 is the highest (i.e., $37 \%$ ), its $\mathrm{CR}$ is much lower as compared to WQ725 (i.e. $35 \% \mathrm{MVF}$ ). This was attributed to the presence of epitaxial ferrite present in FC752 sample. Although the presence of epitaxial ferrite in DP steels and its effect on mechanical properties have been studied by many researchers in the literature [13-15], its influence on corrosion behavior has not been reported yet. As discussed earlier in microstructure section, compositional differences between retained ferrite and epitaxial ferrite are evident. The Mn concentration increases sequentially from retained ferrite, epitaxially ferrite to martensite while the content of Si decreases in the same manner, reported by Korzekwa et al. [12] and recently confirmed by Santofimia et al. [11]. Thus, the galvanic couple formed between retained ferrite and epitaxial ferrite is expected to be weaker than the galvanic couple formed between retained ferrite and martensite. Different contents of alloying elements (i.e., $\mathrm{Mn}, \mathrm{Si}, \mathrm{C}$ ) between retained fer- rite and martensite may result in increased potentials thus propagating micro galvanic corrosion. As shown in Figs. 2a,b, epitaxial ferrite surrounds the martensite phase in the form of rings. It is expected that the potential difference between the phases should be lowered as the concentrations of the phases are similar. From this point of view, lower potential differences should be presented between epitaxial ferrite and martensite as well as between epitaxial and retained ferrite. Therefore, the presence of the epitaxial ferrite may hinder the corrosion by smoothing the compositional fluctuations between the retained ferrite and the martensite. On the other hand, lower CR for WQ715 sample which has no epitaxial ferrite could be explained by having lower MVF. Bhagavathi et al. [21] reported that the $I_{\text {corr }}$ values were similar for all the DP steels having 21, 24 , and $28 \%$ MVF concluding that the MVF up to $28 \%$ had little effect on the corrosion rate of DP steels.

In addition, stresses developed during rapid cooling may be another reason for the increased corrosion rate. Our previous TEM study [13] showed that the dislocation density of the specimen WQ725 was higher than that of the specimen FC752. This means that higher dislocation density causes higher stress levels in the WQ725 specimens. By considering the stressinduced corrosion, it can be speculated that stresses due to higher dislocation density may trigger corrosion in the specimen WQ725.

\section{Conclusions}

1. The martensite volume fraction increases with an increase in intercritical annealing temperature.

2. The slow cooling rate for FC752 allows the epitaxial ferrite to grow on the existing ferrite attributed to increasing in intercritical annealing temperature or decreasing in cooling rate.

3. Mass loss of all the investigated specimens remained almost similar for the early stages (i.e., up to 3 days) after which the mass loss was deviated as the immersion time prolonged. The mass loss is approximately $30 \%$ less for FC752 at 28-day exposure time as compared to WQ725.

4. The $I_{\text {corr }}$ values deviated in the range between 2.11 and $3.11 \mu \mathrm{A} \mathrm{cm}^{-2}$ for WQ715, FC725, and FC752 samples while $I_{\text {corr }}$ value of WQ725 was around $14.5 \mathrm{\mu A} \mathrm{cm}^{-2}$.

5 . Corrosion rate increased with increasing martensite volume fraction. However, this phenomenon was inhibited in the epitaxial ferrite containing samples, attributed to the presence of epitaxial ferrite hindering corrosion by smoothing the compositional fluctuations between retained ferrite and martensite as well as reduced dislocation density. 


\section{References}

[1] Rashid, M. S.: In: Formable HSLA and Dual-Phase Steels. Ed.: Davenport, A. T. Chicago, Illinois, AIME 1977, p. 1.

[2] Koo, J. Y., Thomas, G.: In: Formable HSLA and DualPhase Steels. Ed.: Davenport, A. T. Chicago, Illinois, AIME 1977, p. 40.

[3] Morrow, J. W., Tither, G., Buck, R. M.: In: Formable HSLA and Dual-Phase Steels. Ed.: Davenport, A. T. Chicago, Illinois, AIME 1977, p. 151.

[4] Hayami, S., Furukawa, T., Gondoh, H., Takechi, H.: In: Formable HSLA and Dual-Phase Steels. Ed.: Davenport, A. T. Chicago, Illinois, AIME 1977, p. 167.

[5] Davies, R. G., Magee, C. L.: In: Structure and Properties of Dual-Phase Steels. Eds.: Kot, R. A., Morris, J. W. New Orleans, AIME 1977, p. 1.

[6] Hayami, S., Furukawa, T.: In: Proceedings of Microalloying 75 . Vanitec, London 1975, p. 78.

[7] Rashid, M. S.: GM 980X-A Unique High Strength Sheet Steel with Superior Fromability. SAE Preprint No. 760206. 1976, p. 938.

[8] Davies, R. G.: Metall. Trans. A, 9A, 1978, p. 671. doi:10.1007/BF02659924

[9] Speich, G. R., Miller, R. L.: In: Structure and Properties of Dual-Phase Steels. Eds.: Kot, R. A., Morris, J. W. New Orleans, AIME 1977, p. 145.

[10] Huppi, G. S., Matlock, D. K.: Scripta Metall., 14, 1980, p. 1239. doi:10.1016/0036-9748(80)90264-1

[11] Santofimia, M. J., Kwakernaak, C., Sloof, W. G., Zhao, L., Siestma, J.: Mater. Charact., 61, 2010, p. 937. doi:10.1016/j.matchar.2010.06.006

[12] Korzekwa, D. A., Matlock, D. K., Krauss, G.: Metall. Trans. A, 13, 1982, p. 2061. doi: 10.1007/BF02645952

[13] Salamci, E., Kabakci, F.: J. Fac. Eng. Arch. Gazi Univ., 26, 2011, p. 263. doi:10.17341/gummfd.76139.

[14] Sarwar, M., Ahmad, E., Qureshi, K. A., Manzoor, T.: Mater. Des., 28, 2007, p. 335. $\underline{\text { doi:10.1016/j.matdes.2005.05.019 }}$
[15] Jeong, W. C., Kim, C. H.: Metall. Trans. A, 18, 1987, p. 629. doi:10.1007/BF02649478

[16] Demir, B., Candan, S., Salamci, E., Erdoğan, M.: In: IXth Int. Corrosion Symp. and Exhibition. Ed.: Koc, T. Ankara, The Corrosion Association 2004, p. 495.

[17] Trejo, D., Monterio, P., Thomas, G., Wang, X. Y.: Cem. Concr. Res., 24, 1994, p. 1245. doi: 10.1016/0008-8846(94)90109-0

[18] Zhang, C., Cai, D., Liao, B., Zhao, T., Fan, Y.: Mater. Lett., 58, 2004, p. 1524. doi:10.1016/i.matlet.2003.10.018

[19] Sarkar, P. P., Kumar, P., Manna, M. K., Chakraborti, P. C.: Mater. Lett., 59, 2005, p. 2488. doi:10.1016/i.matlet.2005.03.030

[20] Osorio, W. R., Peixoto, L. C., Garcia, L. R., Garcia, A.: Mater. Corros., 60, 2009, p. 804. doi: $10.1002 / \mathrm{maco} .200805181$

[21] Bhagavathi, L. R., Chaudhari, G. P., Nath, S. K.: Mater. Des., 32, 2011, p. 433. doi:10.1007/BF02660523 doi:10.1016/j.matdes.2010.06.025

[22] Andrews, K. W.: J. Iron and Steel Inst., 203, 1965, p. 721.

[23] Lawson, R. D., Matlock, D. K., Krauss, G.: Metallogr., 13, 1980, p. 71. doi: 10.1016/0026-0800(80)90023-3

[24] Lawson, R. D., Matlock, D. K., Krauss, G.: In: Fundamentals of Dual Phase Steels. Eds.: Kot, R. A., Bramfitt, B. L. New York, AIME 1981, p. 347.

[25] Jeong, W. C., Kim, C. H.: Scripta Metall., 19, 1985, p. 37. doi:10.1016/0036-9748(85)90261-3

[26] Geib, M. D., Matlock, D. K., Krauss, G.: Met. Trans. A, 11, 1980, p. 1683. doi:10.1007/BF02660523

[27] Huppi, G. S., Matlock, D. K., Krauss, G.: Scripta Metall., 14, 1980, p. 1239. doi: 10.1016/0036-9748(80)90264-1

[28] Cramer, S. D., Covino, B. S., Jr. (Eds.): ASM International Metals Handbook. Corrosion. 9th Edition. Metals Park, ASM International 1987. 